\title{
Mutant prevention concentrations of doripenem and meropenem alone and in combination with colistin (polymyxin E), levofloxacin and tobramycin in Pseudomonas aeruginosa
}

\author{
George G Zhanel $\mathrm{PhD}^{1,2,3}$, Vibhu Vashisht $\mathrm{BSc}^{1}$, Ed Tam $\mathrm{MD}^{1,3}$, Daryl J Hoban $\mathrm{PhD}^{1,3}$, James A Karlowsky PhD ${ }^{1,3}$
}

GG Zhanel, V Vashisht, E Tam, DJ Hoban, JA Karlowsky. Mutant prevention concentrations of doripenem and meropenem alone and in combination with colistin (polymyxin E), levofloxacin and tobramycin in Pseudomonas aeruginosa. Can J Infect Dis Med Microbiol 2009;20(Suppl A):67A-71A.

BACKGROUND: With a limited number of available antimicrobial agents to treat Pseudomonas aeruginosa infections, the prevention of emergence of antimicrobial resistance and its subsequent spread is critical. In the present study, the mutant prevention concentration (MPC) of doripenem was examined and compared with meropenem for its ability to prevent resistant mutant selection for $P$ aeruginosa when used alone and in combination with the other antipseudomonal agents colistin (polymyxin E), levofloxacin and tobramycin.

OBJECTIVE: To determine if two antimicrobial agents that possessed different mechanisms of action and separate demonstrated activities against $P$ aeruginosa would produce a reduced MPC in combination compared with the MPC of each agent alone.

METHODS: Twelve clinical isolates of $P$ aeruginosa were plated on Mueller-Hinton agar containing $1 \times, 2 \times, 4 \times, 8 \times, 16 \times$ and $32 \times$ the doripenem, imipenem or meropenem minimum inhibitory concentration (MIC), and also on agar containing doripenem or meropenem in combination with either tobramycin $(6 \mu \mathrm{g} / \mathrm{mL})$, colistin $(2 \mu \mathrm{g} / \mathrm{mL}$ or $8 \mu \mathrm{g} / \mathrm{mL})$, levofloxacin $(8 \mu \mathrm{g} / \mathrm{mL})$ or azithromycin $(0.4 \mu \mathrm{g} / \mathrm{mL})$. The MPC for each antimicrobial agent-isolate combination was defined as the lowest antibiotic concentration that prevented the visible growth of mutant colonies at $48 \mathrm{~h}$ of incubation. The MPC/MIC $(\mu \mathrm{g} / \mathrm{mL})$ ratio was defined as the ratio of the MPC obtained to the original MIC.

RESULTS: The MPC/MIC ratios of doripenem alone ranged from 8 to 32 for the twelve isolates tested compared with 32 for two isolates and greater than 32 for 10 isolates with imipenem, and 32 for three isolates and greater than 32 for nine isolates with meropenem. All antimicrobials tested exhibited markedly elevated MPCs compared with their original MICs with MPC/MIC ratios of 8 to 32 for doripenem, 32 to greater than 32 for imipenem, 32 to greater than 32 for meropenem, 32 to greater than 32 for colistin (tested at $2 \mu \mathrm{g} / \mathrm{mL}$ ), 8 to 16 for levofloxacin and 8 to 32 for tobramycin. When a second antimicrobial was used in combination with doripenem, the MPC/MIC ratio decreased up to twofold for doripenem combined with colistin $(2 \mu \mathrm{g} / \mathrm{mL})$, decreased four- to 16 -fold for doripenem combined with colistin ( $8 \mu \mathrm{g} / \mathrm{mL})$, decreased eight- to 32-fold for doripenem combined with levofloxacin, and decreased four- to 16 -fold for doripenem combined with tobramycin. Adding a second antimicrobial in combination with meropenem resulted in the following decreases in MPC/MIC: no decrease for meropenem combined with colistin $(2 \mu \mathrm{g} / \mathrm{mL})$, four to greater than eightfold decrease for meropenem combined with colistin $(8 \mu \mathrm{g} / \mathrm{mL})$, four- to 16 -fold decrease for meropenem combined with levofloxacin, and two- to 16-fold decrease for meropenem combined with tobramycin. For all antimicrobial combinations tested, doripenem yielded greater decreases in MPC/MIC ratios than did meropenem.

CONCLUSION: The present study found that individual antipseudomonal antimicrobial agents tested against 12 clinical isolates of $P$ aeruginosa had eight- to greater than 32-fold higher MPCs than MICs, that combining doripenem or meropenem with a second active antipseudomonal agent with a different mechanism of action was more effective at preventing resistance selection than the two agents used individually, and finally, that doripenem was less likely than both imipenem and meropenem to select for spontaneous resistance mutants of $P$ aeruginosa.

Key Words: Doripenem; Meropenem; Mutant prevention; P aeruginosa

Les concentrations de prévention de mutation du doripénem et du méropénem seuls et en association avec la colistine (polymyxine E), la lévofloxacine et la tobramycine en cas de Pseudomonas aeruginosa

HISTORIQUE : Étant donné le nombre limité d'antimicrobiens disponibles pour traiter les infections à Pseudomonas aeruginosa, il est essentiel de prévenir l'émergence d'une résistance aux antimicrobiens et sa propagation subséquente. Dans la présente étude, on a examiné la concentration de prévention de mutation (CPM) du doripénem et on l'a comparée avec le méropénem pour sa capacité de prévenir la sélection d'une mutation résistante au $P$ aeruginosa lorsqu'il est utilisé seul et en association avec les autres antipseudomonaux, soit la colistine (polymyxine E), la lévofloxacine et la tobramycine.

OBJECTIF : Déterminer si deux antimicrobiens aux mécanismes d'action différents et aux activités démontrées distinctes contre le $P$ aeruginosa assurent une réduction de la CPM s'ils sont associés, par rapport à la CPM de chaque agent utilisé seul.

MÉTHODOLOGIE : Douze isolats cliniques de $P$ aeruginosa ont été cultivés sur une gélose Mueller-Hinton contenant une, deux, quatre, huit, 16 et 32 fois la concentration minimale inhibitrice (CMI) de doripénem, d'imipénem ou de méropénem, et également sur une gélose contenant du

suite page suivante

${ }^{1}$ Department of Medical Microbiology, Faculty of Medicine, University of Manitoba; ${ }^{2}$ Departments of Medicine; ${ }^{3}$ Clinical Microbiology, Health Sciences Centre, Winnipeg, Manitoba

Correspondence: Dr. George G Zhanel, Clinical Microbiology, Health Sciences Centre, MS673-820 Sherbrook Street, Winnipeg, Manitoba R3A 1R9. Telephone 204-787-4902, fax 204-787-4699, e-mail ggzhanel@pcs.mb.ca 
doripénem ou du méropénem en association avec de la tobramycine $(6 \mu \mathrm{g} / \mathrm{mL})$, de la colistine $(2 \mu \mathrm{g} / \mathrm{mL}$ ou $8 \mu \mathrm{g} / \mathrm{mL})$, de la lévofloxacine $(8 \mu \mathrm{g} / \mathrm{mL})$ ou de l'azithromycine $(0,4 \mu \mathrm{g} / \mathrm{mL})$. La CPM de chaque association d'antimicrobien et d'isolat était définie comme la plus basse concentration d'antibiotique qui prévenait la croissance visible de colonies mutantes à 48 heures d'incubation. Le ratio CPM/CMI (en $\mu \mathrm{g} / \mathrm{mL}$ ) était défini comme le ratio de la CPM obtenue par rapport à la CMI originale.

RÉSULTATS : Le ratio CPM/CMI de doripénem seul variait de huit à 32 pour les 12 isolats vérifiés, par rapport à 32 pour deux isolats et plus de 32 pour dix isolats associés à l'imipénem, et 32 pour trois isolats et plus de 32 pour neuf isolats associés au méropénem. Tous les antimicrobiens vérifiés présentaient des CPM très élevées par rapport à leur CMI originale, avec un ratio CPM/CMI de huit à 32 pour le doripénem, de 32 et plus pour l'imipénem, de 32 et plus pour le méropénem, de 32 et plus pour la colistine (vérifiée à $2 \mu \mathrm{g} / \mathrm{mL}$ ), de huit à 16 pour la lévofloxacine et de huit à 32 pour la tobramycine. Lorsqu'un deuxième antimicrobien s'ajoutait au doripénem, le ratio CPM/CMI pouvait diminuer d'un facteur pouvant atteindre deux pour le doripénem associé à la colistine
$(2 \mu \mathrm{g} / \mathrm{mL})$, de quatre à 16 associé à la colistine $(8 \mu \mathrm{g} / \mathrm{mL}$, de huit à 32 associé à la lévofloxacine, et de quatre à 16 associé à la tobramycine. L'ajout d'un deuxième antimicrobien en association avec le méropénem entraînait les diminutions suivantes du ratio CPM/CMI : pas de diminution pour le méropénem associé à la colistine $(2 \mu \mathrm{g} / \mathrm{mL})$, d'un facteur de quatre à plus de huit associé à la colistine $(8 \mu \mathrm{g} / \mathrm{mL})$, de quatre à 16 associeé à la lévofloxacine, et d'un facteur de deux à 16 associé à la tobramycine. Pour toutes les associations d'antimicrobiens vérifiées, le doripénem entraînait une diminution plus importante du ratio CPM/CMI que le méropénem.

CONCLUSION : La présente étude a établi que chaque antimicrobien antipseudomonal vérifié contre 12 isolats cliniques de $P$ aeruginosa avait une CPM de huit à plus de 32 fois plus élevée que les CMI, que l'association de doripénem et de méropénem à un deuxième antipseudomonal au mécanisme d'action différent était plus efficace pour prévenir la sélection d'une résistance que les deux agents utilisés seuls et, enfin, que le doripénem était moins susceptible de sélectionner des mutations résistantes spontanées au $P$ aeruginosa que l'imipénem ou le méropénem.
P seudomonas aeruginosa continues to be an important cause of infections in Canadian and American hospitals $(1,2)$. With a limited number of available antimicrobial agents to treat $P$ aeruginosa infections, the prevention of emergence of antimicrobial resistance and its subsequent spread is critical (3). Carbapenems such as meropenem and imipenem/cilastatin are used alone and in combination with other agents to treat patients with $P$ aeruginosa infections (4). A recent in vitro study (5) reported that when antipseudomonal antimicrobials are tested alone against $P$ aeruginosa, resistant subpopulations can be selected, leading to dramatic increases in minimum inhibitory concentrations (MICs).

It has been suggested that manipulating antimicrobial agent dosing strategies may limit the selection of resistant mutants and preserve antimicrobial activity (6-9). This concept has been well studied extensively with fluoroquinolones and is known as the mutant selection window (6-9). The mutant selection window is bounded by the MIC at its lower end and the organism's mutant prevention concentration (MPC) at its upper end. The MPC is the drug concentration required to prevent the emergence of all single-step mutants in a population of approximately $10^{10}$ bacterial cells $(5,6)$. If antimicrobial dosing strategies maintain concentrations above the MPC for a sufficient duration (ideally the entire dosing interval), a reduced risk of selecting antimicrobial-resistant mutants may result. The MPC has recently been validated in vivo (10).

The use of two antimicrobial agents in combination compared with one agent alone has been reported to lower an organism's MPC $(5,11)$. To survive exposure to two antimicrobial agents, an organism must develop simultaneous resistance to both agents, assuming that both agents act via different modes of action and that the organism is initially susceptible to both agents $(5,11)$.

In the present study, we examined the MPC of doripenem, and compared it with meropenem in its ability to prevent resistant mutant selection for $P$ aeruginosa when used alone and in combination with the other antipseudomonal agents colistin (polymyxin E), levofloxacin and tobramycin. Our hypothesis was that two antimicrobial agents that possessed different mechanisms of action and separately displayed activity against $P$ aeruginosa would demonstrate a reduced MPC in combination compared with each individual antimicrobial agent MPC.
METHODS

Isolates and antimicrobials tested

Twelve isolates of $P$ aeruginosa collected during the Canadian Ward Surveillance Study (CANWARD 2007) and the Canadian Intensive Care Unit (CAN-ICU) surveillance studies $(12,13)$ were used. MICs were determined in triplicate, on separate days, by broth microdilution using cation-adjusted MuellerHinton broth in accordance with Clinical and Laboratory Standards Institute guidelines (14). The antimicrobials tested were doripenem (Ortho McNeil, USA), levofloxacin (Ortho McNeil, USA), tobramycin (Sigma, USA), imipenem/cilastatin (Merck, USA), meropenem (AstraZeneca, USA), colistin (polymyxin E) (Sigma, USA) and azithromycin (Pfizer Inc, USA).

\section{MPC studies}

Isolates were grown overnight on Mueller-Hinton agar at $35^{\circ} \mathrm{C}$ in ambient air, inoculated into Mueller-Hinton broth, incubated for $3 \mathrm{~h}$ at $35^{\circ} \mathrm{C}$, and centrifuged to achieve inocula of approximately $10^{10}$ colony-forming units per $100 \mu \mathrm{L}$ (5). Initial inocula were quantified through serial dilution and plating. Mutants were selected by plating inocula (approximately $10^{10}$ colony-forming units) in $100 \mu \mathrm{L}$ on Mueller-Hinton agar containing $1 \times, 2 \times, 4 \times, 8 \times, 16 \times$ and $32 \times$ the doripenem, imipenem or meropenem MIC alone, or using either doripenem or meropenem in combination with either tobramycin $(6 \mu \mathrm{g} / \mathrm{mL})$, colistin $(2 \mu \mathrm{g} / \mathrm{mL}$ or $8 \mu \mathrm{g} / \mathrm{mL})$, levofloxacin $(8 \mu \mathrm{g} / \mathrm{mL})$ or azithromycin $(0.4 \mu \mathrm{g} / \mathrm{mL})$. Mutants were not selected at the MPC or at concentrations above the MPC. The concentrations of antimicrobials used in combination with doripenem and meropenem were selected to reflect their peak serum concentrations obtained after standard dosing in healthy adults $(5,15)$. While $2 \mu \mathrm{g} / \mathrm{mL}$ best approximates this concentration for colistin, $8 \mu \mathrm{g} /$ $\mathrm{mL}$ was also tested because this concentration may be attained with more aggressive dosing regimens. Inocula were also plated on Mueller-Hinton agar containing $1 \times, 2 \times, 4 \times, 8 \times, 16 \times$ and $32 \times$ the MIC of each noncarbapenem antimicrobial, except azithromycin. Azithromycin was not tested alone due to technical issues with preparing agar plates containing greater than $256 \mu \mathrm{g} / \mathrm{mL}$ of this agent. Antimicrobial-containing plates were incubated for $48 \mathrm{~h}$ and antimicrobial-free plates (used to determine initial inocula) for $24 \mathrm{~h}$ in ambient air at $35^{\circ} \mathrm{C}$. Colony counts were then performed. All experiments were repeated in 
TABLE 1

Pseudomonas aeruginosa minimum inhibitory concentrations (MICs*) and mutant prevention concentration (MPC)/MIC ratios for antimicrobial agents tested alone

\begin{tabular}{|c|c|c|c|c|c|c|c|c|c|c|c|c|c|c|}
\hline \multirow[b]{2}{*}{ Isolate } & \multicolumn{2}{|c|}{ Doripenem } & \multicolumn{2}{|c|}{ Imipenem } & \multicolumn{2}{|c|}{ Meropenem } & \multicolumn{2}{|c|}{ Azithromycin } & \multicolumn{2}{|c|}{ Colistin } & \multicolumn{2}{|c|}{ Levofloxacin } & \multicolumn{2}{|c|}{ Tobramycin } \\
\hline & MIC & MPC/MIC & MIC & MPC/MIC & MIC & MPC/MIC & MIC & MPC/MIC & MIC & $\mathrm{MPC} \mathrm{MIC}^{\dagger}$ & MIC & MPC/MIC & MIC & MPC/MIC \\
\hline 46139 & 0.25 & 8 & 1 & 32 & 0.25 & $>32$ & $>256$ & NT & 1 & $>32$ & 0.5 & 8 & 1 & 16 \\
\hline 49674 & 0.25 & 16 & 2 & $>32$ & 0.25 & $>32$ & $>256$ & NT & 1 & 32 & 1 & 8 & 1 & 8 \\
\hline 59690 & 0.125 & 8 & 1 & $>32$ & 0.25 & $>32$ & $>256$ & NT & 2 & $>32$ & 2 & 8 & 0.25 & 16 \\
\hline 62958 & 0.25 & 8 & 0.25 & $>32$ & 0.25 & 32 & $>256$ & NT & 2 & $>32$ & 4 & 8 & 0.5 & 16 \\
\hline 63930 & 0.25 & 8 & 2 & $>32$ & 0.25 & $>32$ & $>256$ & NT & 2 & 32 & 4 & 8 & 0.25 & 32 \\
\hline 64225 & 0.25 & 32 & 2 & $>32$ & 0.5 & $>32$ & $>256$ & NT & 2 & $>32$ & 0.5 & 8 & 0.5 & 16 \\
\hline 64713 & 0.5 & 32 & 2 & $>32$ & 0.5 & $>32$ & $>256$ & NT & 4 & 32 & 2 & 8 & 1 & 16 \\
\hline 68031 & 0.25 & 16 & 2 & $>32$ & 0.5 & 32 & $>256$ & NT & 2 & $>32$ & 0.5 & 8 & 1 & 16 \\
\hline 64120 & 0.25 & 16 & 2 & 32 & 0.5 & 32 & $>256$ & NT & 4 & $>32$ & 4 & 16 & 1 & 32 \\
\hline 64900 & 0.25 & 32 & 2 & $>32$ & 0.5 & $>32$ & $>256$ & NT & 4 & $>32$ & 0.5 & 8 & 1 & 32 \\
\hline 65724 & 0.25 & 32 & 2 & $>32$ & 0.5 & $>32$ & $>256$ & NT & 4 & $>32$ & 1 & 8 & 0.5 & 16 \\
\hline 66313 & 1 & 32 & 2 & $>32$ & 0.5 & $>32$ & $>256$ & NT & 4 & 32 & 4 & 16 & 1 & 16 \\
\hline
\end{tabular}

${ }^{*}$ MICs are in $\mu \mathrm{g} / \mathrm{mL} ;{ }^{\dagger} 2 \mu \mathrm{g} / \mathrm{mL}$ colistin. NT Not tested

TABLE 2

Pseudomonas aeruginosa mutant prevention concentration/minimum inhibitory concentration ratios for antimicrobial agents tested alone and in combination with doripenem or meropenem

\begin{tabular}{|c|c|c|c|c|c|c|c|c|}
\hline Isolate & Doripenem & Meropenem & $\begin{array}{l}\text { Doripenem + } \\
\text { Colistin }\end{array}$ & $\begin{array}{l}\text { Meropenem + } \\
\text { Colistin }\end{array}$ & $\begin{array}{l}\text { Doripenem + } \\
\text { Levofloxacin }\end{array}$ & $\begin{array}{c}\text { Meropenem + } \\
\text { Levofloxacin }\end{array}$ & $\begin{array}{c}\text { Doripenem + } \\
\text { Tobramycin }\end{array}$ & $\begin{array}{c}\text { Meropenem + } \\
\text { Tobramycin }\end{array}$ \\
\hline 46139 & 8 & $>32$ & $8^{\star}, 2^{\dagger}$ & $>32^{*}, 8^{\dagger}$ & 0.5 & 2 & 1 & 4 \\
\hline 49674 & 16 & $>32$ & $8^{*}, 2^{\dagger}$ & $>32^{*}, 8^{\dagger}$ & 0.5 & 2 & 1 & 4 \\
\hline 59690 & 8 & $>32$ & $8^{\star}, 1^{\dagger}$ & $>32^{*}, 8^{\dagger}$ & 0.5 & 4 & 1 & 4 \\
\hline 62958 & 8 & 32 & $8^{*}, 1^{\dagger}$ & $32^{*}, 4^{\dagger}$ & 0.5 & 2 & 1 & 2 \\
\hline 63930 & 8 & $>32$ & $8^{\star}, 2^{\dagger}$ & $>32^{*}, 8^{\dagger}$ & 0.5 & 2 & 1 & 2 \\
\hline 64225 & 32 & $>32$ & $32^{\star}, 4^{\dagger}$ & $>32^{*}, 8^{\dagger}$ & 1 & 2 & 2 & 4 \\
\hline 64713 & 32 & $>32$ & $32^{*}, 2^{\dagger}$ & $>32^{*}, 8^{\dagger}$ & 1 & 2 & 2 & 4 \\
\hline 68031 & 16 & 32 & $16^{*}, 1^{\dagger}$ & $32^{*}, 8^{\dagger}$ & 0.5 & 0.5 & 1 & 4 \\
\hline 64120 & 16 & 32 & $16^{\star}, 2^{\dagger}$ & $32^{\star}, 4^{\dagger}$ & 1 & 2 & 1 & 2 \\
\hline 64900 & 32 & $>32$ & $32^{\star}, 4^{\dagger}$ & $>32^{\star}, 16^{\dagger}$ & 1 & 2 & 2 & 2 \\
\hline 65724 & 32 & $>32$ & $32^{\star}, 4^{\dagger}$ & $>32^{*}, 8^{\dagger}$ & 0.5 & 1 & 2 & 4 \\
\hline 66313 & 32 & $>32$ & $32^{\star}, 2^{\dagger}$ & $>32^{*}, 8^{\dagger}$ & 1 & 2 & 4 & 8 \\
\hline
\end{tabular}

${ }^{*}$ colistin, $2 \mu \mathrm{g} / \mathrm{mL} ;{ }^{\dagger}$ colistin, $8 \mu \mathrm{g} / \mathrm{mL}$

triplicate, on separate days. All repetitions of MPC experiments resulted in MPC values within one doubling-dilution (twofold difference in MPC). The MPC for each drug-isolate combination was defined as the lowest antibiotic concentration that prevented the visible growth of mutant colonies following $48 \mathrm{~h}$ of incubation (5). The MPC/MIC $(\mu \mathrm{g} / \mathrm{mL})$ ratio was used to represent the data obtained, defined as the ratio of the MPC obtained to the original MIC (5).

\section{RESULTS}

The MICs of the antimicrobial agents tested against the 12 isolates of $P$ aeruginosa and MPC/MIC ratios are displayed in Table 1. The MPC/MIC of doripenem ranged from 8 to 32. For imipenem, MPC/MIC ratios were 32 for two isolates and greater than 32 for 10 isolates. Similarly, for meropenem, the MPC/MIC were 32 for three isolates and greater than 32 for nine isolates. For each isolate tested, doripenem demonstrated a twofold to greater than fourfold lower MPC/MIC ratio than both imipenem and meropenem. For all antimicrobials tested alone, MPCs were markedly elevated compared with MICs with MPC/MIC ratios of 8 to 32 for doripenem, 32 to greater than 32 for imipenem, 32 to greater than 32 for meropenem, 32 to greater than 32 for colistin (tested at $2 \mu \mathrm{g} / \mathrm{mL}$ ), 8 to 16 for levofloxacin, and 8 to 32 for tobramycin.

When a second antimicrobial was used in combination with doripenem, the MPC/MIC ratio did not decrease for the combination of doripenem and azithromycin (data not shown), decreased up to twofold for doripenem combined with colistin ( $2 \mu \mathrm{g} / \mathrm{mL})$, decreased four- to 16 -fold for doripenem combined with colistin $(8 \mu \mathrm{g} / \mathrm{mL})$, decreased eight- to 32-fold for doripenem combined with levofloxacin, and decreased four- to 16-fold for doripenem combined with tobramycin (Table 2). Adding a second antimicrobial in combination with meropenem resulted in the following decreases in MPC/MIC: no decrease for meropenem combined with azithromycin (data not shown), no decrease for meropenem combined with colistin $(2 \mu \mathrm{g} / \mathrm{mL})$, four- to greater than eightfold decrease for meropenem combined with colistin $(8 \mu \mathrm{g} / \mathrm{mL})$, four- to 16 -fold decrease for meropenem combined with levofloxacin, and twoto 16-fold decrease for meropenem combined with tobramycin. For all antimicrobial combinations tested, doripenem yielded greater decreases in MPC/MIC ratios than did meropenem. 


\section{DISCUSSION}

The present study generated three important observations. First, our results demonstrated that when individual antipseudomonal antimicrobial agents are tested alone against $P$ aeruginosa, all agents have markedly increased MPCs (MPC/MIC ratios eight- to greater than 32-fold) compared with their MIC (Table 1). This suggests that using an agent alone to treat $P$ aeruginosa infections may result in elevated MPC/MIC ratios in vivo with the potential for resistance development and bacteriological failure. Elevated MPC/MIC ratios and the potential for resistance may be less likely to occur when treating patients with urinary tract infections because high concentrations of carbapenems, levofloxacin and aminoglycosides are attained in the urinary tract, which may prevent resistance development.

The second observation was that combination treatment with either doripenem or meropenem and a second antimicrobial agent (each agent possessing independent activity against $P$ aeruginosa and acting with a different mechanism of action) was more effective at preventing mutant selection for $P$ aeruginosa than the two agents used individually (Table 2). This was demonstrated by large decreases in MPC/MIC ratios (four- to 32-fold) when doripenem or meropenem were used in combination with colistin $(8 \mu \mathrm{g} / \mathrm{mL})$, levofloxacin or tobramycin. This observation that dual-drug therapy for isolates of $P$ aeruginosa that are susceptible to both antimicrobial agents may prevent the selection of resistant mutants has been previously reported both in vitro and in vivo $(5,16)$. It should be mentioned that combination therapy with two antimicrobial agents with different mechanisms of action is not a new idea; it has been reported to result in reduced mortality in $P$ aeruginosa bacteremia (16). What is novel about combination MPC is the concept of using specific combinations to not simply increase bacterial killing, but to actually maximize resistance prevention using a specific combination of antimicrobial agents.

The third observation was that doripenem was less likely than both imipenem and meropenem to select for resistance in $P$ aeruginos $a$ as manifested by its twofold to greater than fourfold lower MPC/MIC ratios compared with imipenem and meropenem. This observation was consistent and occurred whether doripenem and meropenem were used alone or in combination with colistin $(8 \mu \mathrm{g} / \mathrm{mL})$, levofloxacin or tobramycin. Why would doripenem be less likely to select for resistance in $P$ aeruginosa than imipenem or meropenem? Microbiologically, studies have demonstrated that $\mathrm{MIC}_{90} \mathrm{~S}$

\section{REFERENCES}

1. Walkty A, DeCorby M, Nichol K, et al. Antimicrobial susceptibility of Pseudomonas aeruginosa isolates obtained from patients in Canadian intensive care units as part of the Canadian National Intensive Care Unit study. Diagn Microbiol Infect Dis 2008;61:217-21.

2. Lockhart SR, Abramson MA, Beekman SE, et al. Antimicrobial resistance among gram-negative bacilli as causes of infections in intensive care unit patients in the United States between 1993. 2004. J Clin Microbiol 2007;45:3352-9.

3. Rubinstein E, Zhanel GG. Anti-infectives research and development problems challenges and solutions: The clinical practitioner perspective. Lancet Infect Dis 2007;7:69-70.

4. Zhanel GG, Wiebe R, Dilay L, et al. A review of the carbapenems. Drugs 2007;67:1027-52.

5. Zhanel GG, Mayer M, Laing N, et al. Mutant prevention (concentration that inhibits $90 \%$ of isolates) for doripenem and meropenem tested against $P$ aeruginos $a$ are similar $(8 \mu \mathrm{g} / \mathrm{mL}$ and $16 \mu \mathrm{g} / \mathrm{mL}$, respectively) and that both agents are more potent than imipenem (4). Davies et al (17) recently reported that doripenem demonstrated greater affinity than imipenem for penicillin-binding protein (PBP) 2 and PBP3 in $P$ aeruginosa. Doripenem also has slightly greater affinity than meropenem against both PBP2 and PBP3 with one of the two P aeruginosa strains (ATCC 27853) studied (17). Mushtaq et al (18) performed single-step mutational studies (analogous to our MPC studies) and reported that mutant selection with doripenem occurred with fewer strains versus other agents including meropenem and imipenem, and that the final multiple of the MIC killing all cells was lower with doripenem than meropenem and imipenem and never exceeded four times the MIC. Sakyo et al (19) assessed the potencies of doripenem, imipenem and meropenem in preventing the emergence of carbapenem-resistant mutants of $P$ aeruginosa. In performing mutational studies, these investigators documented both lower mutational frequencies of doripenem compared with both imipenem and meropenem as well as lower MICs of doripenem versus imipenem and meropenem in the carbapenem-resistant $P$ aeruginosa selected (19). In fact, these investigators could not select doripenem-resistant $P$ aeruginosa on agar plates containing doripenem but could select doripenem-resistant strains on plates containing imipenem and meropenem (19). Their carbapenem-resistant $P$ aeruginosa exhibited reductions in an outer membrane protein with a molecular weight of approximately $48,000 \mathrm{Da}$, which the authors speculated was outer membrane protein $\mathrm{D} 2$.

\section{CONCLUSIONS}

The present study found that individual antipseudomonal antimicrobial agents tested against 12 clinical isolates of $P$ aeruginosa had eight- to greater than 32-fold higher MPCs than MICs, that combining doripenem or meropenem with a second active antipseudomonal agent with a different mechanism of action was more effective at preventing resistance selection than the two agents used individually, and finally, that doripenem was less likely than both imipenem and meropenem to select for spontaneous resistance mutants of $P$ aeruginosa.

ACKNOWLEDGEMENTS: Funding for this study was provided by the by the University of Manitoba and Ortho McNeil.

concentration of levofloxacin alone and in combination with azithromycin ceftazidime colistin (polymyxin E) meropenem piperacillin/tazobactam and tobramycin in Pseudomonas aeruginosa. Antimicrob Agents Chemother 2006;50:2228-30.

6. Drlica K. The mutant selection window and antimicrobial resistance. J Antimicrob Chemother 2003;52:11-7.

7. Zhao X, Drlica, K. Restricting the selection of antibiotic-resistant mutants: A general study derived from fluoroquinolone studies. Clin Infec Dis 2001;33(Suppl 3):147-56.

8. Smith HJ, Walters M, Hisanaga T, et al. Mutant prevention concentrations for single-step fluoroquinolone-resistant mutants of wild-type, efflux-positive, or ParC or GyrA mutation-containing Streptococcus pneumoniae isolates. Antimicrob Agents Chemother 2004;48:3954-8.

9. Firsov AA, Vostrov SN, Lubenko IY, et al. In vitro 
pharmacodynamic evaluation of the mutant selection window hypothesis using four fluoroquinolones against Staphylococcus aureus. Antimicrob Agents Chemother 2003;47:1604-13.

10. Almeida $D$, Nuermberger $E$, Tyagi $S$, et al. In vivo validation of the mutant selection window hypothesis with moxifloxacin in a murine model of tuberculosis. Antimicrob Agents Chemother 2007;51:4261-6.

11. Firsov AA, Vostrov SN, Lubenko IY, et al. Prevention of the selection of resistant Staphylococcus aureus by moxifloxacin plus doxycycline an in vitro dynamic model: An additive effect of the combination. Int J Antimicrob Agents 2004;23:451-6.

12. Zhanel GG, DeCorby M, Laing N, et al. Prevalence of antimicrobial-resistant pathogens in Canadian hospitals: Results of the CANWARD 2007 study. Can J Infect Dis Med Microbiol 2009;20(Suppl A):9A-19A.

13. Zhanel GG, DeCorby M, Laing N, et al. Antimicrobial resistant pathogens in intensive care units in Canada: Results of the Canadian National Intensive Care Unit (CAN-ICU) Study, 2005-2006. Antimicrob Agents Chemother 2008;52:1430-7.

14. Clinical and Laboratory Standards Institute. Methods for dilution antimicrobial susceptibility tests for bacteria that grow aerobically, 7th edn. CLSI/NCCLS M100-S15. Approved standard M7-A7. Clinical and Laboratory Standards Institute, Wayne, PA.

15. Kucers A, Scrowe S, Grayson ML, et al. The Use of Antibiotics: A Clinical Review of Antibacterial, Antifungal, and Antiviral drugs, 5th edn. Boston, Massachusetts: Butterworth-Heinemann, 1997.

16. Safdar N, Handelsman J, Maki DG. Does combination antimicrobial therapy reduce mortality in gram-negative bacteremia? A meta-analysis. Lancet Infect Dis 2004:4:519-27.

17. Davies TA, Shang W, Bush K, et al. Affinity of doripenem and comparators to penicillin-binding proteins in Escherichia coli and Pseudomonas aeruginosa. Antimicrob Agents Chemother 2008;52:1510-2.

18. Mushtaq S, Ge Y, Livermore DM. Doripenem versus Pseudomonas aeruginosa in vitro: Activity against characterized isolates mutants and transconjugants and resistance selection potential. Antimicrob Agents Chemother 2004;48:3086-92.

19. Sakyo S, Tomita H, Tanimoto K, eta al. Potency of carbapenems for the prevention of carbapenem resistant mutants of Pseudomonas aeruginosa. J Antibiot 2006;59:220-8. 


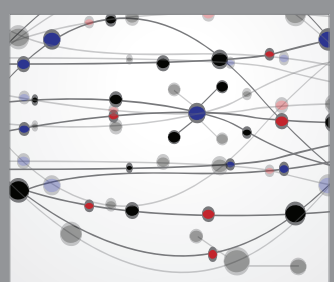

The Scientific World Journal
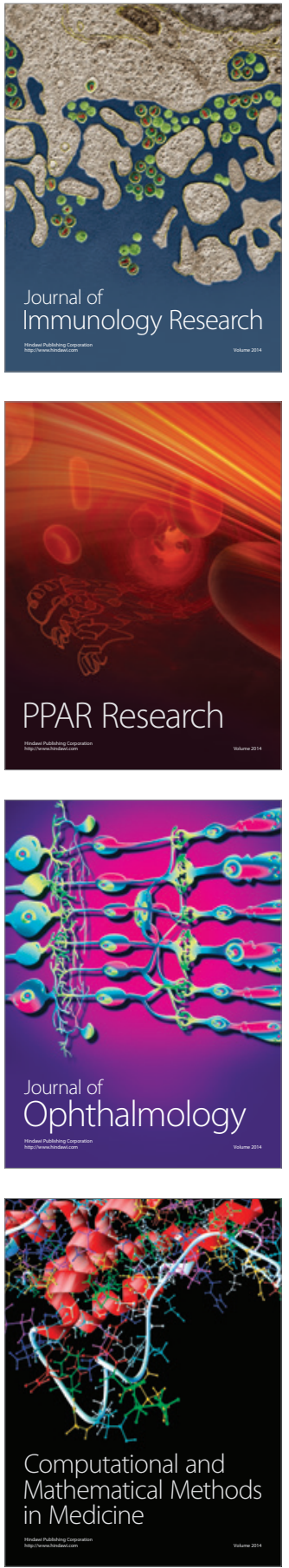

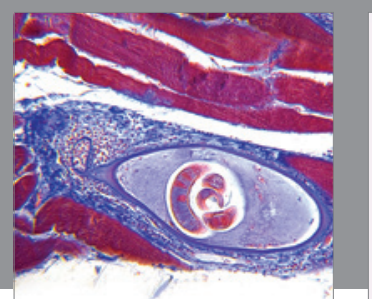

Gastroenterology Research and Practice

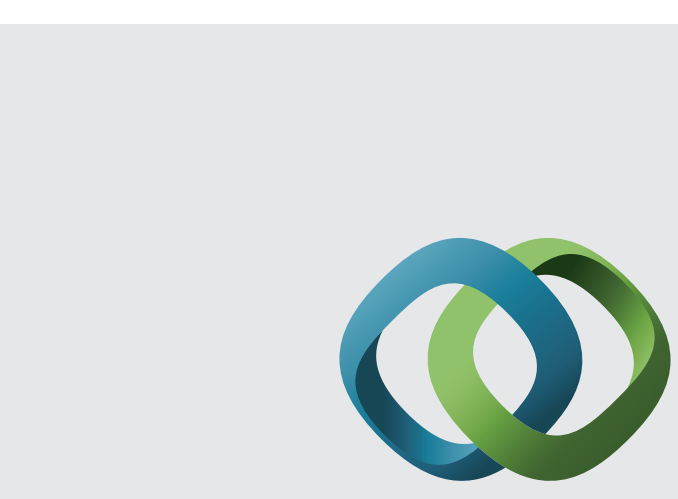

\section{Hindawi}

Submit your manuscripts at

http://www.hindawi.com
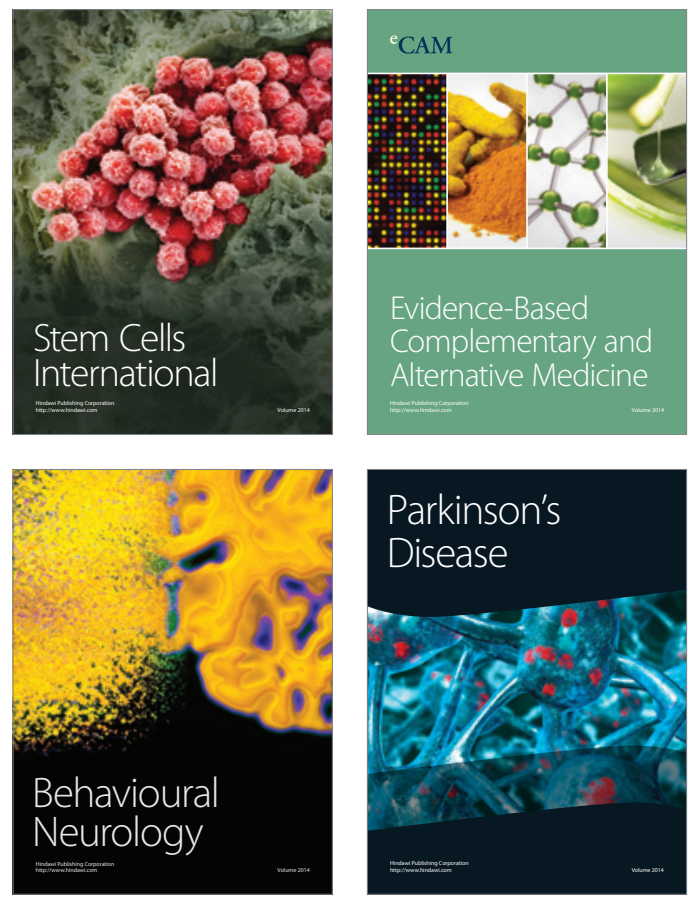
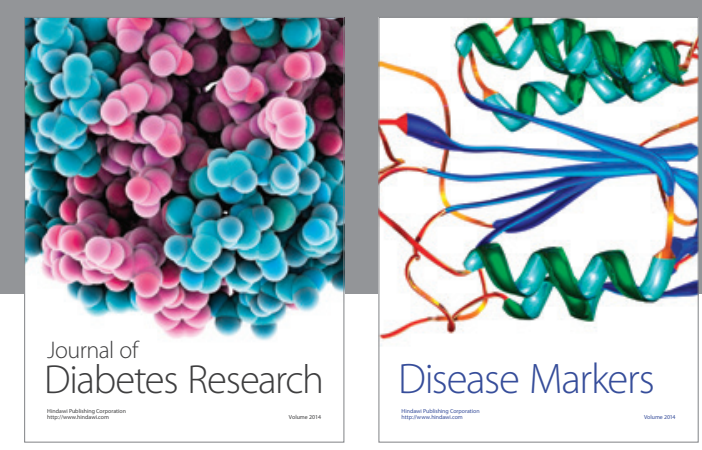

Disease Markers
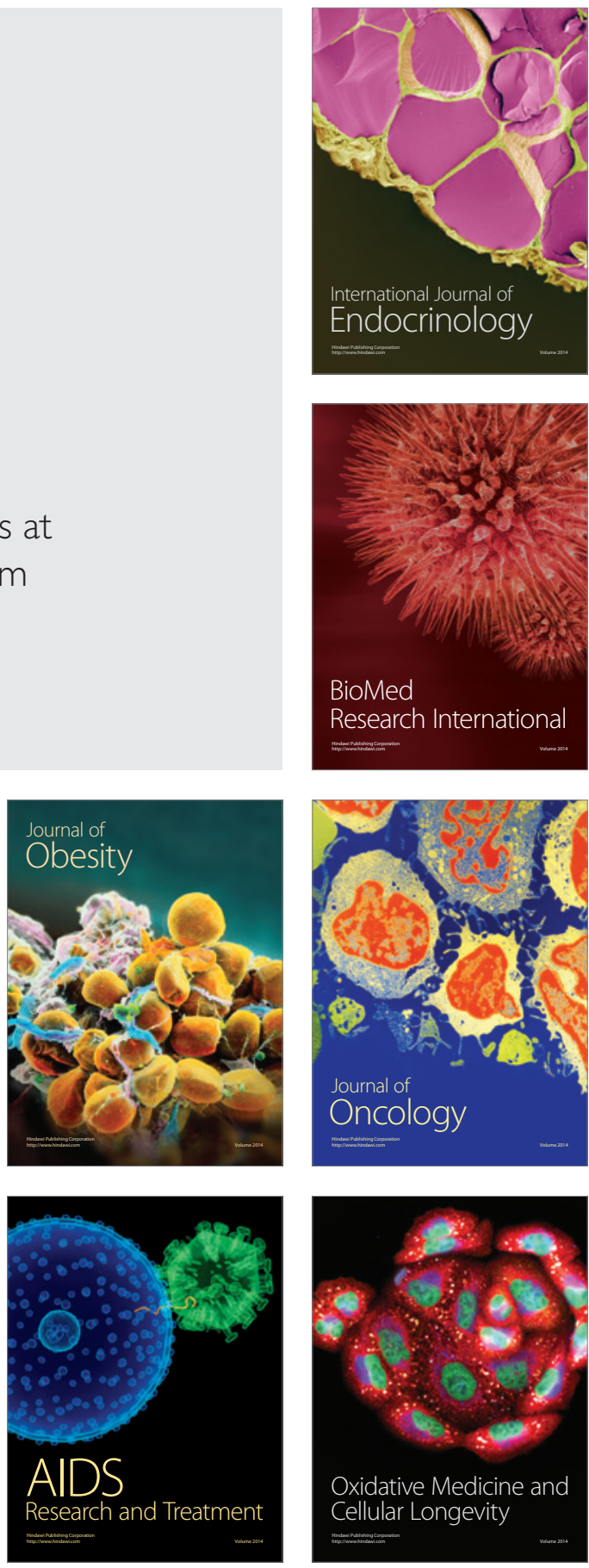